\title{
Por que é difícil fazer o verdadeiro "Governo-eletrônico"
}

\author{
M. G. FuGINI \\ P. Maggiolini \\ B. PAgAmicI
}

Politecnico di Milano

\begin{abstract}
Resumo
O objetivo deste trabalho é apresentar um framework que permita entender o complexo e ambíguo fenômeno do "Governo-eletrônico" (eGovernment) e seus diferentes modelos. Adicionalmente, serão discutidas as principais dificuldades de se fazer o verdadeiro "Governo-eletrônico" e as maneiras de superá-las. De fato, há algum tempo a utilização das ICT, especialmente "de forma inovadora", nas Administrações Públicas tem sido categorizada sob a etiqueta de "Governo-eletrônico" (eGovernment), dando então a impressão (se não a ilusão) de um autêntico salto de qualidade (em eficiência e eficácia) no exercício da função de governo por parte das diferentes entidades públicas. Na realidade, na maioria dos casos, e na melhor das hipóteses, o que aconteceu e continua acontecendo é somente uma potencialização no fornecimento e no aproveitamento dos serviços públicos, mas ainda não um verdadeiro melhoramento das atividades de governo.
\end{abstract}

\section{Palavras-chave}

Governo-eletrônico, tecnologia da informação; administração pública.

\section{Why is it difficult to make the true "Electronic Government"?}

\begin{abstract}
The objective of this paper is to present a framework, which allows to understand the complex and ambiguous phenomenon of the "Electronic Government" (eGovernment) and the different models to understand it. Furthermore, this paper presents the main difficulties of making the true "Electronic Government" and a way to surpass them. In fact, it has some time the use of the ICT, especially "of innovative form", in the Public Administrations received the label of "electronic Government" (eGovernment), giving the impression (if not a illusion) of an authentic jump of quality lin efficiency and effectiveness] in the exercise of government function by different public entities. Actually, in the majority of the cases, and in the best hypotheses, what it happened is only an enhancement in the supply and the exploitation of public services, but not a true improvement of government activities.
\end{abstract}

Key words

Electronic Government (eGovernment); information technology; public administration. 


\section{INTRODUC̣ÃO}

Em grande síntese, podemos dizer que as diferentes entidades públicas desenvolvem (em um mix que depende de cada particular entidade) essencialmente duas funções: 1) fornecem "serviços públicos" a algumas categorias ou à totalidade de cidadãos; e 2) "governam" coletividades (territorialmente ou setorialmente definidas), promovendo e garantindo o interesse coletivo (em relação a saúde, educação, segurança, habitação, ambiente, etc.), assim como são, em última instância, concretamente determinadas e acordadas pelos próprios cidadãos (através da sua participação - em suas várias formas na "política").

É óbvio que entre as duas funções há uma ligação, em particular a primeira função é instrumento a serviço da segunda, entretanto, é também verdade que a função de governo não se esgota especificamente no fornecimento (em particular, o direto) de serviços públicos. Reduzir a essência da função de governo à prestação de serviços (ainda que públicos) seria como reduzir os cidadãos a consumidores (ainda que também de serviços públicos).

Às funções citadas, podemos acrescentar uma terceira, que cada Administração deve de qualquer forma desenvolver, que é aquela de "administrar a si mesma" (incluídos - obviamente - os relativos "atos": tautologicamente poderia-se dizer que uma Administração existe enquanto executa "atos administrativos"!).

Portanto, as Administrações Públicas modernas, que sempre prestaram "serviços públicos" de várias naturezas, às vezes também de natureza informativa (pode-se pensar nas mais variadas certificações), desde quando tem estado disponível a Tecnologia da Informação e Comunicação (TIC), elas a têm utilizado de forma progressiva, seja para fornecer serviços de natureza informativa, seja de forma mais geral para dar apoio e favorecer o fornecimento e o aproveitamento dos serviços públicos (ainda que simplesmente favorecendo a um conhecimento personalizado e atualizado dos mesmos).

Em medida muito pequena - até o presente momento a TIC tem sido utilizada para dar apoio e melhorar a função de governo (nos dois sentidos, seja em relação à coletividade governada quanto por parte dela). Estranhamente, há algum tempo, a utilização, especialmente "a de forma inovadora", da Tecnologia da Informação e Comunicação (TIC) na Administração Pública está englobada sob o rótulo de "Governo-eletrônico" (eGovernment), dando então a impressão (se não a ilusão) de um autêntico salto de qualidade (de eficiência e eficácia) no exercício da função de governo por parte das diferentes Entidades Públicas. Na realidade, na maioria dos casos até agora, e na melhor das hipóteses, o que aconteceu e continua acontecendo é somente uma potencialização e melhoria no fornecimento e no aproveitamento dos serviços de interesse público.

É de se perguntar se estamos diante somente de um (perdoável) equívoco terminológico (bastaria substituir e-Governo por e-Administração) (Governo-eletrônico por Administração-eletrônica), ou mesmo de uma operação ideológica (aquela de transformar o cidadão em um simples "consumidor", e então toda a política em um processo "consumístico", isto é, na escolha - com o voto - por parte de cada indivíduo particular, de quem, entre os vários políticos e seus respectivos partidos, lhe "oferece" os serviços que individualmente mais os interessam, eliminando completamente a "velha" idéia que nos remete a Aristóteles - que diz que o bem-estar individual é fruto sobretudo do bem-estar da "cidade").

A tese em que se quer trabalhar e pesquisar, e neste artigo dar uma contribuição de enquadramento teórico e metodológico, é que a TIC, as "novas" tecnologias da informação e comunicação e as correspondentes inovações organizacionais na Administração Pública sejam, e sobretudo possam ser, um verdadeiro instrumento de Governo-eletrônico, no sentido pleno da palavra.

\section{UMA TIPOLOGIA DAS FUNC̣ÕES DA ADMINISTRAC̣̃̃O PÚBLICA}

Para compreender as lógicas que estão sujeitas à utilização da TIC na Administração Pública e delinear os modelos prevalentes da adoção e difusão da mesma, e sobretudo apontar as dificuldades que tornam difícil fazer um verdadeiro governo eletrônico, podemos - como já antecipado - antes de tudo classificar as várias funções de uma Administração Pública em:

- funções da administração interna da Administração Pública (gestão de pessoal, dos próprios recursos financeiros, etc.)

- funções da produção de serviços para as várias categorias de cidadãos administrados (empresas e operadores socioeconômicos incluídos): serviços hídricos, de limpeza urbana, sanitários, escolares, de administração judiciária, de segurança pública, etc.

- funções do governo (da coletividade e do território de competência), através de instrumentos que vão desde planos reguladores urbanísticos às leis que regulamentam o mercado de trabalho, por exemplo.

Diante de tal classificação de funções, podemos adotar uma tipologia particular dos Sistemas de Informação presentes na administração pública. 


\section{UMA TIPOLOGIA DOS SISTEMAS DE INFORMAĈ̣̃O DA ADMINISTRAC̣ÃO PÚBLICA}

Os Sistemas de Informação na Administração Pública tendem a se desenvolver segundo dois tipos fundamentais: os sistemas de informação chamados "administrativos" e aqueles chamados "estatísticos".

\section{a) Sistemas de Informação administrativos}

Os Sistemas de Informação do tipo administrativo (Fig.1) respondem a uma função de gestão da Administração Pública que é bem definida. As fontes de informação nestes sistemas são documentos e subprodutos de atos administrativos. Estes sistemas são orientados para um uso na maior parte das vezes preciso e particular. Em tais sistemas está claro quem usa as informações, por que as usa, isto é, para cumprir que papel estes sistemas servem.

Exemplos de Sistemas de Informação administrativos são aqueles dos registros civis da população, do estado civil, do registro de imóveis, do Departamento de Trânsito, e das empresas nas Juntas Comerciais.

\section{b) Sistemas de Informação estatísticos}

Os Sistemas de Informação do tipo estatístico não têm usuários definidos precisamente, são "tomadores de decisão" genéricos. Em tais sistemas, a reunião das informações é essencialmente fundada em metodologias tipo censo, sondagens, pesquisas, etc. (Fig.2).

Exemplos de Sistemas de Informação estatísticos são aqueles sobre natalidade, mortalidade, movimentos demográficos e censos da população. Certos Sistemas são obviamente parte administrativos e parte estatísticos.

Figura1: Sistemas de Informação administrativos.

\section{SISTEMAS DE INFORMAÇÃO ADMINISTRATIVOS}

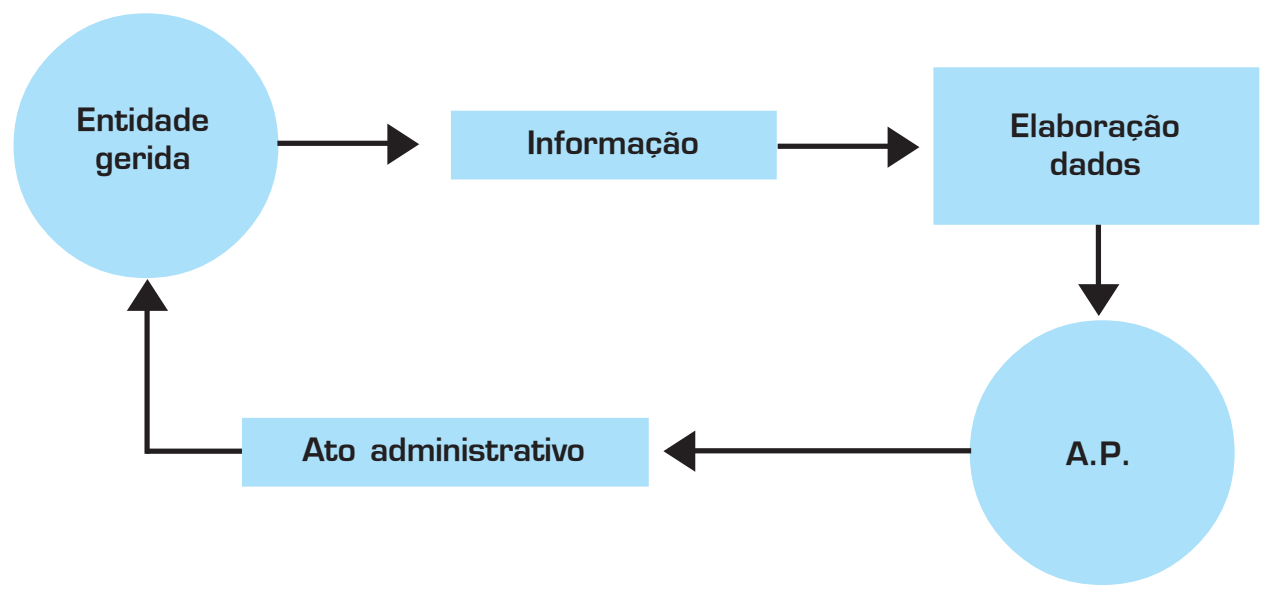

Figura 2: Sistemas de informação estatísticos.

\section{SISTEMAS DE INFORMAÇÃO ESTATÍSTICOS}

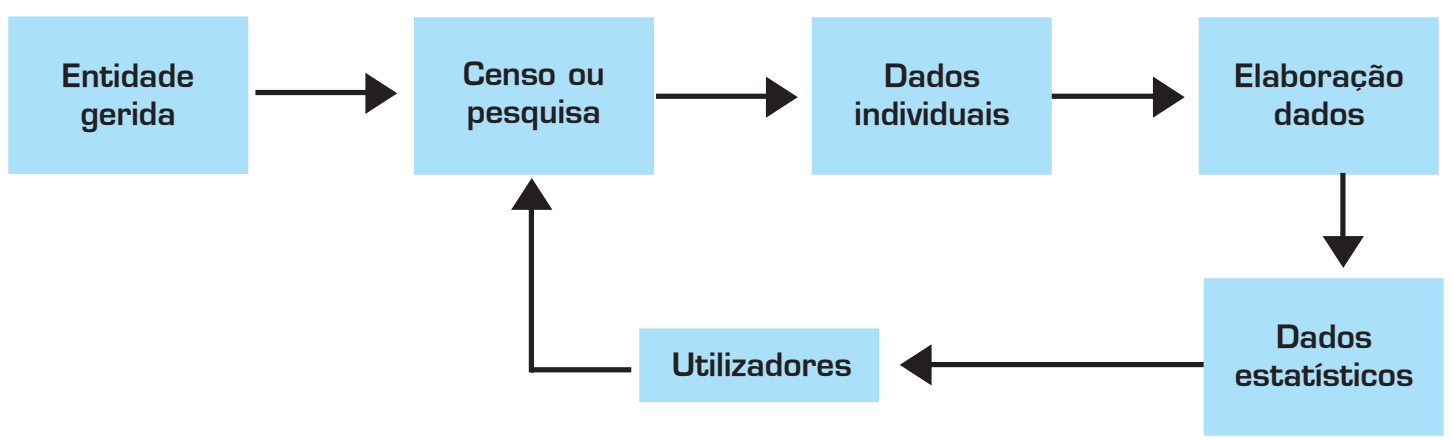


Em particular são usados, para finalidades estatísticas, subprodutos das atividades administrativas.

\section{UMA CLASSIFICACC̃̃O DOS SISTEMAS SOCIAIS}

Para identificar corretamente os diferentes modelos e estratégias de informatização da Administração Pública, é oportuno apresentar ainda uma outra classificação. Existe de fato o problema do âmbito e das dimensões em que se coloca o Sistema de Informação da Entidade pública ("municipal", "estadual", "regional", etc.): trata-se de algo que se refere à cidade, à região, etc. como entidade ou como coletividade territorial.

Os sistemas sociais podem ser classificados por nível de integração.

\section{a) Sistemas hiperintegrados}

Existem sistemas sociais que podemos chamar "hiperintegrados". Entre os componentes de tais sistemas, o nível - a força - da integração é muito grande. Se considerarmos a família, o grupo, o clã, por exemplo, esses grupos na realidade não têm problemas de sistemas de informação, ao menos de sistemas de informação formais, exatamente por causa da natureza das ligações que intercorrem entre os seus membros.

Os partidos políticos, as verdadeiras relações de "clientela" entre administradores e administrados, certos "feudos" internamente às administrações, e assim por diante, representam fenômenos sociais classificáveis, segundo o nosso esquema, como sistemas hiperintegrados.

O sistema de informações do sistema hiperintegrado, do "clã" (como poderia ser de um partido), é frequentemente informal; a troca de informação e as comunicações acontecem em um contexto onde conta a transmissão das tradições, a interiorização dos valores e normas, uma forte "personalização" das relações interpessoais.

As "tradições" representam a memória da organização hiperintegrada, acessível somente depois de um longo processo de socialização.

Gostaríamos de ressaltar como a organização do tipo "clã" não é estranha ao sistema "Administração Pública", entendida como sistema "político". Na base do funcionamento de tais sistemas estão de fato relações de confiança, de compartilhamento de valores e normas.

\section{b) Sistemas mesointegrados}

As organizações (em um sentido mais restrito, isto é, aquelas que são chamadas de "burocracias") são sistemas sociais mesointegrados.

Como mesointegrada pode ser definida uma empresa industrial: cada repartição tem como finalidade a produ- ção de uma certa parte para montar um produto e vendêlo: toda a empresa tem como objetivo obter um lucro e remunerar a estrutura que produz e vende.

Um outro exemplo de sistema mesointegrado é justamente aquele de uma Administração Pública, uma prefeitura, por exemplo: cada assessoria ou unidade de uma Prefeitura deve fornecer um certo serviço para a população, o qual a Prefeitura administra para permitir-lhe desenvolver-se em termos sociais e econômicos.

\section{c) Sistemas hipointegrados}

Como hipointegrada pode ser definida uma coletividade territorial, por exemplo uma cidade ou um estado. Cada unidade socioeconômica (agrícola, industrial, comercial, de serviços públicos, etc.) nela inserida produz um bem ou um serviço que não tem por si só como finalidade o interesse da coletividade inteira, mas a sobrevivência, o desenvolvimento da específica unidade socioeconômica (uma empresa agrícola, uma empresa industrial, uma família, etc.).

Exemplos de sistemas hipointegrados são, portanto, todas as coletividades, como uma cidade, um estado, uma população, uma etnia, uma nação.

\section{Uma comparação entre sistemas mesointegrados e hipointegrados}

Uma cidade ou um estado, então, como entidades, são sistemas mesointegrados e, como coletividades territoriais, são sistemas hipointegrados. Vale a pena, portanto, aprofundar-nos nas diferenças que existem entre sistemas mesointegrados e sistemas hipointegrados.

Como pode ser visto no quadro esquemático a seguir, nos sistemas mesointegrados (que são "artefatos sociais", isto é, sistemas sociais construídos propositadamente com um objetivo) a estrutura organizacional que regulamenta os subsistemas é especificada e o grau de autonomia dos subsistemas é definido formalmente. Pensemos nos organogramas.

A dinâmica do sistema é "observável": existe uma "memória" localizada da organização, constituída pelos procedimentos, regulamentos, métodos de trabalho, etc., mais ou menos facilmente acessível, e é também "controlável", isto é, existem instrumentos institucionais e organizacionais para pilotar $o$ sistema de um estado para o outro: os dirigentes do sistema mesointegrado podem "ordenar" a um dependente que faça certas coisas, podem "encomendar" algumas compras, etc.

Os sistemas hipointegrados criam, no entanto, problemas de "observabilidade" (de conhecimento), pois a "memória" é muito fracionada: de fato os atores são muitos e, sobretudo, têm autonomia de decisão e de iniciativa muito elevada. A "estrutura" dos sistemas hi- 
pointegrados existe, no sentido de que existem ligações de troca entre a agricultura, a indústria manufatureira, os serviços, etc. e a Administração Pública, mas tal estrutura é volátil, muito "desfigurada" e dificilmente controlável.

Nos sistemas hipointegrados existem, portanto, também problemas de "controlabilidade". Os administradores de uma cidade ou de um estado não são "patrões" dos cidadãos: não podem "ordenar" a um agricultor o que cultivar ou a uma empresa o que produzir ou comprar.

Quando se quer implementar um Sistema de Informação de uma entidade pública (por exemplo, uma prefeitura, um estado), freqüentemente se imagina tal entidade como a uma estrutura burocrática, isolada do contexto territorial que se opera para a obtenção dos fins institucionais, seguindo procedimentos definidos com base em leis e normas. Existe uma tendência a se ver então a entidade pública predominantemente como sistema mesointegrado.

Tal imagem é fortemente reducionista. A cidade ou o estado (continuando com os exemplos já citados) são na realidade sobretudo coletividades territoriais, portanto, sistemas hipointegrados: a estrutura burocrática da prefeitura ou do estado é somente uma parte de um sistema muito mais amplo no qual devem ser considerados, em uma visão unitária, os órgãos políticos elegíveis, a comunidade administrada, o inteiro território de competência.

\section{QUATRO "MODELOS" OU MODOS PARA INTERPRETAR A ADMINISTRAC̣ÃO PÚBLICA E CONSEQÜENTES ESTRATÉGIAS DE UTILIZAĈ̣̃O DA TIC}

Com base nas classificações vistas, delineamos esquematicamente quatro "modelos" de concepção da entidade pública (a Administração Pública) e, conse- qüentemente, de desenvolver os Sistemas de Informação e de utilizar a Informática: são os modelos "burocrático", "social", "político", de clã".

\section{Modelo "burocrático"}

Segundo o modelo "burocrático", a Administração Pública é concebida, essencialmente, como entidade que emite normas e que controla suas aplicações: a Administração Pública é garantia da legitimidade das atividades de interesse público da coletividade administrada.

Este modelo pressupõe uma separação rígida entre políticos e funcionários, entre o momento da formulação das premissas de ação e o momento da atuação. A Administração (no seu componente de atuação: o aparato burocrático) estrutura-se porisso baseado no princípio da conformidade aos atos, ou seja, aquilo que é relevante para aos objetivos da ação é aquilo que recai sobre um fato particular, juridicamente predefinido.

Os dados produzidos pela Administração assim concebida são de natureza particular: são constituídos por "atos" formais que registram os fatos, sejam internos ou externos, enquanto se referem a fatos juridicamente predefinidos.

Conseqüentemente, aplica-se a Informática sobretudo, por exemplo, na gestão de impostos e tributos, nas certificações, na gestão dos atos oficiais e juridicamente relevantes da Administração (deliberações, regulamentos, ordens, concessões, autorizações, licenças, etc.).

\section{Modelo "social"}

Segundo o modelo "social", a Administração é concebida essencialmente como uma organização que fornece, direta e/ou indiretamente, serviços aos cidadãos administrados.

\section{SISTEMAS MESOINTEGRADOS}

- Todo subsistema tem claramente por finalidade o objetivo comum

- A estrutura é estabelecida

- O grau de autonomia dos subsistemas é formalmente definido

- A dinâmica do sistema é suficientemente "observável" e "controlável"

- "Conhecimento" ("memória") localizado

\section{SISTEMAS HIPOINTEGRADOS}

- Todo subsistema não tem por si, como finalidade, $o$ interesse de todo o sistema

- A estrutura não é evidente

- Elevada autonomia dos subsistemas

- A dinâmica do sistema é pouco "observável" e "controlável"

- "Conhecimento" ("memória") fracionado 
A utilização da Tecnologia da Informação (informática e telemática) é vista como um modo de fornecer mais eficazmente estes serviços: o desejo é transformar a Administração de uma máquina que registra fatos jurídicos e executa atos administrativos em uma organização a serviço dos cidadãos. Prioritária é a gestão dos serviços à população: realizam-se e informatizam-se arquivos de dados escolares, sanitários, de usuários de serviços sociais, e assim por diante.

Responde a esta lógica também a realização de novos serviços de informação com base na telemática, criados sobretudo pelas entidades públicas para informar sobre os serviços oferecidos, sobre as atividades econômicas, culturais, esportivas, etc. que são realizadas no território de sua competência. Aquilo que hoje chamamos Governo-eletrônico freqüentemente se enquadra bem neste modelo de Administração Pública e relacionado à utilização da TIC.

Os problemas e as perspectivas da TIC como apoio ao modelo "social" da Administração Pública: a "Administração-eletrônica"

Por "Governo-eletrônico" - como já foi dito- se tem freqüentemente entendido substancialmente a Administração Pública com o apoio da TIC. No princípio, este "apoio" se tem concretizado e se consolidado em um potente "back-office", construído principalmente para satisfazer às necessidades específicas das diferentes repartições das Administrações (em apoio ao modelo "burocrático", segundo o nosso esquema). Depois do longo período em que a TIC estava confinada a uma função de apoio à burocracia interna, a sua utilização começou a se mover para o exterior, para a interação com cidadãos e empresas.

Em muitos casos da Administração Pública, a Internet tem significado um salto adiante em disponibilidade os "sites" da "web" estão abertos 24 horas por dia, 7 dias por semana - e em acessibilidade - dando aos cidadãos e empresas acesso à informação e também um certo grau de interação, de casa ou do escritório. O passo sucessivo foi aquele de consentir o preenchimento de módulos, primeiramente baixados via rede e preenchidos à mão, depois diretamente preenchidos "on-line”. Por um certo tempo a tentação foi presumivelmente aquela de simplesmente transferir os processos do papel para a rede, sem repensar os procedimentos em si. Todavia, "repensar" os processos antes de automatizá-los aparece sob a ótica de aproveitar ao máximo a rede de Internet e as tecnologias desenvolvidas ao seu redor.

Esta evolução já é uma realidade na Europa ${ }^{1}$, todavia a sua velocidade de desenvolvimento varia de país para país europeu. Segundo um estudo realizado para a Dire- ção geral, pela Sociedade da Informação da Comissão Européia, sobre os serviços públicos informatizados na Europa (países-membros da União Européia mais Islândia e Noruega), o percentual médio total europeu de desenvolvimento dos serviços públicos na Internet alcançava - no final de 2002 - os $60 \%$.

A Irlanda e a Suécia lideravam a classificação, respectivamente com $87 \%$ e $85 \%$. Diferenças significativas são notadas não somente entre os países, mas - é o que nos interessa - também entre os diferentes tipos de serviços públicos oferecidos. Os serviços destinados às empresas são mais desenvolvidos do que aqueles dirigidos aos cidadãos. No conjunto, os serviços públicos para as empresas registravam uma cifra significativamente mais alta $(72 \%)$ do que aquela que se referia aos serviços para os cidadãos (52\%). Entre as diferentes categorias de serviços públicos, os serviços de arrecadação (taxas, contribuições sociais...) estavam entre os mais desenvolvidos. O serviço público com a maior pontuação neste setor é o serviço de recebimento de ICMS, com 90\%, seguido pela declaração de renda, pelos ônus sociais, pelas taxas sobre as empresas e pelas declarações aduaneiras.

Depois destes vêm os serviços de registro (registro de automóveis, inscrições de novas empresas...).

O terceiro lugar é ocupado pela prestação de serviços. Deste grupo o melhor, em absoluto, é o serviço para pessoas em busca de emprego e a pior pontuação vai para os serviços sanitários.

Os serviços relacionados a autorizações e licenças (passaportes, cartas de motorista...) registram a pontuação mais baixa sempre relacionada ao grau de desenvolvimento. No âmbito deste grupo, a informatização de matrícula na universidade continua a guiar o setor.

Por esta e por outras pesquisas se confirma à idéia de que o assim chamado "Governo-eletrônico" hoje está essencialmente parado no estado de "Administraçãoeletrônica".

Nem todos os problemas foram obviamente resolvidos.

A TIC está há alguns anos lutando para alcançar também a "eficiência" na simplificação e na integração dos serviços oferecidos aos cidadãos e empresas. Grandes resultados - como pudemos ver - foram alcançados sob este ponto de vista. Um denominador comum que está emergindo em muitos países, é que a Internet e o estado atual da TIC permitem à Administração Pública adotar uma abordagem orientada ao cidadão (e às empresas), fornecendo serviços públicos organizados em torno dos seus centros de interesse (como criar uma família, iniciar uma atividade produtiva...) e não em torno da estrutura das próprias Administrações Públicas, como aconteceu e acontece ainda hoje. Neste sentido, muitos problemas estão ainda para ser resolvidos, das "barreiras organiza- 
cionais" (resistência à mudança, também por causa de normas obsoletas) às "barreiras técnicas" (por exemplo, a interoperacionalidade ainda não generalizada por causa de tecnologias herdadas do passado, mas podemos acrescentar a segurança e a exigência de multicanalidade, etc.).

Um dos principais motores do Governo-eletrônico tem sido a grande expectativa da acentuada redução de custos. Na prática esta expectativa tem se mostrado ilusória. Se bem que isoladamente possam ser verificadas algumas economias, no geral tem sido difícil converter as reduções de custo em economias globais. Diferentemente das organizações privadas (que podem de uma certa maneira "escolher" os próprios clientes), a Administração Pública não se pode recusar a interagir com os "clientes custosos", especialmente porque estes são exatamente os que mais dependem dos serviços públicos (lembre, em diferentes campos, dos idosos, dos deficientes, dos doentes, dos pobres, etc.). Na prática, os serviços eletrônicos ("e-Serviços") são adicionados aos serviços existentes, ao invés de promover a sua substituição. Ao considerar o uso de serviços "on-line" do governo-eletrônico, é de fato importante compreender que tais serviços não podem ser vistos como separados dos canais já existentes de fornecimento de serviço "off-line", ou seja, dos canais tradicionais baseados no contato pessoal, que freqüentemente precisam de manutenção ou de serem reforçados para garantir ou incrementar a qualidade do serviço.

Existe, porém, ainda muita margem para intervenção, em termos de "reengenharia" - corretamente interpretada - dos processos internos da Administração Pública, como veremos a seguir.

\section{Necessidade de re-(e)Balancear a Administração Pública}

Como linha de raciocínio, o emprego da TIC por parte da Administração Pública deveria ser guiado somente pelas necessidades da sociedade à qual ela se dirige. Com a finalidade de entender este enfoque, é útil examinar tanto a demanda quanto a oferta da Administração-eletrônica (como preferimos chamar o assim chamado Governo-eletrônico quando NÃO está como apoio às atividades de governo).

Do lado da demanda, a TIC fornece o apoio e potencializa as melhorias de qualidade nos serviços públicos oferecidos nos moldes tradicionais. É importante que a tecnologia não substitua o pessoal, enquanto isto significaria um serviço mais impessoal e de menor qualidade, mas que seja de apoio direto a este pessoal, melhorando a qualidade do serviço e tornando-o mais responsivo às necessidades do cidadão.

Do lado da oferta, grande parte do recente debate está centrado na necessidade da Administração-eletrônica de adotar as práticas rigorosas do "e-Business" e, em relação à reorganização dos processos e estruturas administrativas, de empreender a "reengenharização" dos processos de negócio (Business Process Reengineering BPR).

Em todo caso, muitos consideram (e nós estamos entre eles) que a Administração Pública deva ser diferenciada da lógica puramente empresarial, por diversas razões, inclusive o fato - como já dito - de a Administração Pública não poder escolher os seus "clientes" (palavra que, aliás, deveria ser proibida no caso da Administração Pública!), e que os usuários dos serviços públicos desempenham diferentes papéis, como eleitores, contribuintes e não somente "consumidores". Desta forma, pode ser mais adequado (como sugerido por Millard [Mil03]) uma abordagem de "Reengenharização" dos Processos de Governo (Government Process Reengineering - GPR), ou - preferiremos - APR (Administration Process Reengineering), inspirando-se assim no mundo empresarial, mas também revisando (por exemplo em termos de responsabilidade social) em um contexto de colaboração entre o público, o privado e setores sem fins lucrativos. Efetivamente a Reengenharia de Processos de Negócio (BPR) aplicada diretamente no Governo-eletrônico é freqüentemente considerada um eufemismo para o redimensionamento dos recursos humanos.

De qualquer forma, os melhores exemplos na Europa mostram que a abordagem da GPR (ou APR) se baseia em uma visão mais de longo prazo e melhor compreendida internamente à organização. Espera-se, portanto, por um "rebalanceamento (re-(e)Balanceamento) entre a linha de frente"front-office" e a retaguarda "back-office", como parte de uma política gradual e intencional de deslocar recursos e pessoal, depois de um treinamento específico, dos setores administrativos que se tornaram mais eficientes e otimizados aos serviços que estão mais em contato direto com os cidadãos."

O problema é, portanto, de como redimensionar os serviços internos administrativos (back-office) e incrementar os serviços (front-office), isto é, rebalancear mudando da administração interna (a lógica do modelo "burocrático") aos serviços (segundo a lógica do modelo "social").

Mas este não é certamente o único problema.

\section{Governo-eletrônico "inclusivo"}

Como bem evidenciado, sobretudo por Liikanen [Lii03], o Governo-eletrônico (ainda que na interpretação - reduzida - da Administração-eletrônica) deveria ter por finalidade fornecer serviços públicos de modo a torná-los acessíveis e relevantes para cada cidadão ou empresa. 
Isto significa que o Governo-eletrônico deveria oferecer não somente eficiência (objetivo típico das empresas) mas também e sobretudo equiidade, ou seja direitos iguais e oportunidade de participação para todos e realizar na prática aquilo que Liinkanen chama inclusão.

A eqüidade é importante para a justiça social. A esta concerne aquilo que consideramos justo e imparcial na nossa sociedade.

Mas a inclusão tem também importância do ponto de vista econômico: existe um custo da exclusão em termos de subutilização do potencial humano. Deve ser colocado como objetivo que todos os cidadãos estejam em condições de utilizar os instrumentos do "governo-eletrônico", mesmo que eles tenham menores capacidades "digitais", morem em regiões mais remotas, tenham menores ganhos financeiros, ou tenham exigências especiais mentais ou físicas.

Portanto os Governos têm uma tarefa muito mais difícil que as empresas para ser terminada. Eles não podem escolher os seus clientes (repetimos isso pela enésima vez), devem "servir" a qualquer um. Enquanto as empresas podem mirar-se na eficiência, as Administrações Públicas devem perseguir tanto a eficiência quanto a equiidade. Em termos de tecnologia, isto significa que seria insuficiente oferecer serviços "on-line" somente nos computadores pessoais (PCs). Se bem que o acesso à Internet através dos PCs esteja rapidamente aumentando, a televisão alcança quase todas as famílias. É também provável que o mesmo fato acontecerá com a emergente TV digital interativa. E não nos esqueçamos, obviamente, dos telefones celulares que estão certamente mais difundidos que os PCs.... Em breve será necessária uma aproximação multicanal.

Todavia, gerir de forma consistente e eficiente o fornecimento de um serviço público multicanal "on-line" assim como "offline” será um desafio considerável. De outra forma, o risco de agravar um pesado "Digital Divide" - já presente - também no interior das nações está próximo de acontecer.

\section{Modelo "político"}

Segundo o modelo "político", a Administração, o município ou o Estado, por exemplo, se qualificam como organização de governo político, como centro de programação socioeconômica e planejamento do território.

A natureza específica da entidade pública como organismo do governo político emerge em toda a sua essência.

Sai-se da concepção de município, estado, região, etc. como entidades, para privilegiar município, estado, etc. como âmbitos e coletividades territoriais.

A Administração Pública não é vista somente como uma organização com finalidade jurídica (uma "empresa" com o seu pessoal, uma sua estrutura e os seus "clientes" ou "usuários"), mas também, e sobretudo, como componente de um sistema social e territorial do qual as pessoas e as organizações (unidades sociais) são parte integrante da coletividade administrada.

A TIC é vista como instrumento que ajuda, por um lado, a governar e a controlar melhor os fenômenos territoriais e socioeconômicos, para proporcionar uma base informativa melhor para a programação e para as escolhas políticas, em outras palavras, para a atividade de governo (neste sentido, pode-se falar talvez em Governo-eletrônico) e, por outro lado, a favorecer as relações entre o "Governo" (nas suas várias formas institucionais) e os "cidadãos" (simples e associados), permitindo a participação e o controle das atividades do governo por parte destes últimos (pode-se falar - querendo de eDemocracy, ou Democracia-eletrônica).

\section{O modelo de clã}

Enfim, não apenas não se pode desconsiderar que haja uma concepção "de clã" da Administração, do "poder", presente com as outras, mas que seja uma característica fundamental toda vez que está em jogo a relação de "confiança" eleitores/eleitos, representantes/representados.

Não nos deixemos enganar pela expressão usada aparentemente da forma pejorativa. Queremos simplesmente evidenciar uma modalidade específica de organização das relações de troca de um sistema social que é a organização de clã.

"Partidocracia" (a "ocupação" da Administração Pública por parte dos partidos), "loteamento" e "clientelismo" representam os aspectos degenerados deste modelo organizacional. Mas - como se dizia - todas as vezes que está em jogo uma relação de delegação democrática baseada na confiança estamos na presença de uma lógica "de clã".

Alguma forma de funcionamento "por clã" está presente na maioria dos sistemas sociais: onde porém esta forma organizacional é privilegiada, é claro que existem reflexos também no modo de entender e criar sistemas de informação. Seriam privilegiadas as relações informacionais informais e pessoais no interior dos órgãos eletivos, entre tais organizações e a estrutura burocrática, entre administradores públicos e cidadãos (eleitores), talvez através da organização-partido, associações, grupos de pressão, etc.

Se não se leva em conta este modelo, por clã, corre-se o risco de cortar fora uma fundamental (e importante) parte dos fluxos informativos relevantes também para o governo de uma coletividade.

Neste contexto deveria ser analisado e enquadrado o papel fundamental das Redes Cívicas. 


\section{O GOVERNO-ELETRÔNICO COMO INSTRUMENTO DE GOVERNO E PARTICIPACÃO POLÍTICA}

Retomando-se o já citado Liinkanen, em primeiro lugar o governo-eletrônico deveria tornar possível para os cidadãos acompanhar aquilo que fazem o seus governos centrais, estaduais e locais, participar dos processos decisórios desde suas fases iniciais, verificar que o dinheiro público seja bem gasto.

O governo-eletrônico deveria ser um meio para realizar o Governo aberto: "o Governo-eletrônico deveria ajudar a fazer funcionar melhor a democracia”.

Esta afirmação refere-se ao incremento da participação e do comprometimento democráticos. Os passos dos processos de decisão deveriam ser visíveis e transparentes.

"Governo aberto", portanto, significa também um aumento da transparência e da responsabilidade. A transparência e a abertura são importantes, não somente por causa dos mecanismos democráticos de controle da responsabilidade. É também uma necessidade econômica combater a corrupção e as fraudes. A TIC é particularmente adequada para aumentar a transparência.

\section{POR QUE É DIFÍCIL FAZER O VERDADEIRO "GOVERNO-ELETRÔNICO"}

Ainda querendo visualizar o Governo-eletrônico, não tanto por parte dos cidadãos, mas por parte do próprio Governo, resta compreender as razões que têm impedido até agora a difusão do verdadeiro Governo-eletrônico.

À luz dos modelos de Administração Pública e das estratégias de uso da TIC anteriormente ilustradas, na nossa opinião podemos entender porque são tão pouco difundidos os sistemas informativos de apoio, em particular, às atividades de governo.

Além da falta de "vontade política", com cautela, existem também dificuldades objetivas.

A principal dificuldade na implementação de Sistemas de Informação hipointegrados (e os sistemas do verdadeiro Governo-eletrônico estão entre esses), por exemplo os sistemas de informação territoriais e socioeconômicos, reside no fato de que as informações sobre a coletividade (nas suas várias componentes econômicas, sociais e institucionais) são: 1) apenas minimamente possuídas pela Administração Pública; mas 2) estão nas mãos da própria coletividade; 3 ) estão disseminadas no seio da coletividade; e 4) distribuídas pelo território: o conhecimento sobre os fenômenos econômicos e sociais é fragmentado e mantido em pedaços pelas unidades sociais isoladas.

Como é possível e sob que condições cada unidade social colocaria à disposição da Administração os seus pedaços de conhecimento?

Ao nosso ver, isto é possível somente se os "fornecedores" de informações são de alguma forma, diretamente ou indiretamente, os usuários ou são claramente beneficiários do seu uso.

Em outras palavras, cada unidade social (família, empresa, associação, etc.) está disposta a colocar à disposição a sua parte do "conhecimento" somente se percebe que isto lhe dará vantagens, aliás, isto só acontece se esta "colaboração" está no interior de um processo de troca (considerado no sentido mais amplo, obviamente, no qual cabe também o consenso político): o sistema pode ser colocado em pé e mantido vivo somente se for "pactuado". E' necessário, então, um "pacto informativo"[Cib87] .

\section{A ABORDAGEM "CONTRATUAL": O "PACTO INFORMATIVO"}

Existe uma razão a mais, de fundo, para adotar uma abordagem contratual para a realização e manutenção de um Sistema de Informação, se se vir (como na realidade eles são) os sistemas sociais, e portanto também os sistemas políticos, como redes contratuais de trocas: neste caso os próprios Sistemas de Informação dão suporte aos processos de contratação e regulação das trocas.

O que está em jogo é a maneira própria de entender a atividade de governo (e os relativos sistemas de decisão e informação).

Segundo a abordagem "contratual", os planos e os programas públicos não foram concebidos como instrumentos públicos de intervenção "corretiva" das tendências "espontâneas" de desenvolvimento da coletividade e organização da economia e do território, mas instrumentos de contratação e intermediação entre as partes agentes e interagentes no sistema territorial hipointegrado
MODELOS DE ADMINISTRAC̣ÃO PÚBLICA

Modelo "burocrático"

Modelo "social" (eletrônico)

Modelo "político"

Modelo "de clã"

\section{TIPOS DE GOVERNO-ELETRÔNICO}

Administração-eletrônica

Administração-eletrônica (Serviços Públicos-eletrônicos) verdadeiro Governo-eletrônico (Governo-eletrônico, Democracia-eletrônica)

Democracia-eletrônica, Redes Cívicas 
(partidos políticos, sindicatos, grupos econômicos, outras entidades públicas, etc.). E a definição dos objetivos do governo não é um ato unilateral da Administração Pública, mas sim o fruto de um processo freqüentemente implícito de contratação com os outros atores institucionais, políticos, sociais, econômicos.

E tem mais: a contratação (explícita ou implícita) não se relaciona unicamente aos objetivos, mas também às unidades de medida a se adotar para colocar em evidência necessidades e exigências, para definir padrões. Definitivamente, são objeto de contratação as próprias informações que instrumentam e alimentam as atividades de governo. Caso contrário, não se entenderia, por exemplo, as tentativas pesadas (freqüentemente conseguidas, infelizmente) de condicionar as mídias de massa por parte dos grupos de interesse constituídos e por parte dos próprios governos.

Somente nesta complexa compreensão e redefinição da atividade de "governo" podemos redefinir e trabalhosamente realizar um verdadeiro "Governo-eletrônico" e portanto passar da atual Administração-eletrônica ao Governo-eletrônico e Democracia-eletrônica [cfr Lom02, Len02, Ril03], se quisermos usar estas definições.

Para concluir, usando o nosso esquema, a tabela seguinte permite articular e entender aquilo que é resumido com o conceito sintético de Governo-eletrônico.

\section{- Referências Bibliográficas}

[CG03] Cap Gemini Ernst \& Young, "Overall Report Oct 2001 - Oct 2002. Online Availability of Public Services: How Does Europe Progress? Web Based Survey On Electronic Public Services" (www.capgemini.be/pdf/CGEYEurope OnlinePublicServicesOverallReport).

[Cib87] CIBORRA, C., GASBARRI, G., MAGGIOLINI, P., System design for local authorities: participation based on "Information Contracts", in
DOQUERTY, P., FUCHS-KITTOWSKI, K. KOLM, P., MATHIASSEN, L. (ed.s), System design for human development and productivity: participation and beyond. North-Holland, Amsterdam, 1987.

[Cha04] CHAHIN, A.; CUNHA, M.A:; KINGHT, P.T.; LEMOS, PINTO S. - egov.Br. A proxima revolução brasileira - Eficiência, qualidade e democracia: o governo eletrônico no Brasil e no mundo - Pearson Prentice Hall, São Paulo, 2004
[Len02] LENIHAN, D.G. - Realigning Governance: From E-Government to EDemocracy - Centre for Collaborative Government, Ottawa, April 2002.

[Lii03] LIIKANEN, E. E-Government and the European Union, Rivista online UPGrade, v. IV, n. 2, Abril 2003.

[Lom02] e-lomb@rdia - dall'egovernment all'e-governance Documento strategico 2002-2005 perla diffusione della Società dell'informazione in Lombardia.
[Mil03] MILLARD, J. Il ri-eBilanciamento del Governo, Rivista online UPGrade sul, v. IV, n. 2, Abril 2003.

[Ril03]RILEY, T.B. The information society: the role of information in the emerging global e-government, egovernance and e-democracy environments. Commonwealth Centre For Electronic Governance, Ottawa, 2003.

\section{- Agradecimentos}

Agradecemos a revisão técnica da tradução deste artigo feita pelo Prof. Clovis Alvarenga.

\section{- Sobre os autores}

\section{G. Fugini}

Politecnico di Milano

Dipartimento di Elettronica e Informazione

E-mail: mariagrazia.fugini

\section{P. Maggiolini}

Politecnico di Milano

Dipartimento di Ingegneria Gestionale

Endereço: Piazza da Vinci, 3220133 Milano

E-mail: piercarlo.maggiolini@polimi.it

\section{B. Pagamici}

Politecnico di Milano

Dipartimento di Ingegneria Gestionale

Endereço: Piazza da Vinci, 3220133 Milano

E-mail: bpagami@tin.it 